\title{
Recombinant allergens in immunotherapy of asthma
}

\author{
Taiebeh Mohammadi Farsani,2, Reza Yaghubi-tabar1', Gholamreza Mohammadi Farsani2,3
}

\author{
'Department of Medical Biotechnology, Isfahan (Khorasgan) Branch, Islamic Azad University, Isfahan, Iran. \\ ${ }^{2}$ Minimally Invasive Surgery Research Center, Iran University of Medical Sciences, Tehran, Iran. \\ ${ }^{3}$ Department of Clinical Nutrition, School of Nutritional Sciences and Dietetics, Tehran University of Medical Sciences, Tehran, Iran. \\ *Correspondence to : Gholamreza Mohammadi Frasani, (mohammadigh53@gmail.com) \\ (Submitted: 18 March 2020 - Revised version received: 06 April 2020 - Accepted:04 May 2020 - Published online: 26 June 2020)
}

\begin{abstract}
Asthma is a chronic inflammatory disorder caused by T-cell-mediated inflammation within airways. The prevalence of allergic diseases is rapidly increasing so that knowing allergens (characterization and types) and strategies for asthma management, prevention, and treatment are very important. The most important strategy is production of recombinant allergens. Many of the problems associated with using natural allergenic products for allergy diagnosis and treatment can be overcome with use of genetically engineered recombinant allergens. Various recombinant allergens are now emerging as strong candidates for allergen-specific immunotherapy. Extrinsic asthma (a type of asthma) may respond to immunotherapy such as using of recombinant allergens. These exciting novel therapies provide not only promise of new therapies for asthma but also valuable tools for investigation of asthma mechanisms. This review describes strategies for asthma management, prevention, and treatment and especially recombinant allergens and also recent progresses in the molecular biology of recombinant allergens and then advantage and disadvantage of these allergens are explained. There are many methods for producing allergens such as extraction of serum, Ro/SS-A anti-Ro/SS-A system, using Solid-Phase Immunoadsorption system and finally recombinant technology for producing recombinant allergens. Recombinant allergens can be expressed in many systems such as bacteria, yeast, insect cells, animal cells, and transgenic plants. We describe recombinant allergens produced in these systems. The obtained results hold promise that recombinant allergen-based immunotherapy will improve current immunotherapy practice and may open possibilities for new treatment strategies and possibly even for prophylactic vaccination.
\end{abstract}

\section{Introduction}

Asthma, as a type of allergic diseases, is a common chronic inflammatory disease of the airways characterized by variable and recurring symptoms, reversible airflow obstruction, and bronchospasm ${ }^{1}$ and common symptoms of it include wheezing, coughing, chest tightness, and shortness of breath. ${ }^{2}$ The prevalence of asthma has increased significantly since the 1970s. As of 2011, 235-300 million people were affected globally, including about 250,000 deaths. ${ }^{3}$ It is estimated to affect as many as 339 million people worldwide according to a report from the Global Asthma Network published in 2018. ${ }^{4}$ Globally, asthma is ranked 16th among the leading causes of years lived with disability and 28th among the leading causes of burden of disease. ${ }^{4,5}$ It is estimated that the number of people with asthma worldwide may be as high as 334 million according to a report from the Global Asthma Network published in 2014. ${ }^{4}$ Pathophysiological mechanisms of asthma contain the changes occurring in the airways that consist of a chronic eosinophilic and lymphocytic inflammation, together with epithelial and structural remodeling and proliferation, and altered matrix proteins, which underlie airway wall narrowing and bronchial hyper responsiveness (BHR). Several inflammatory mediators released from inflammatory cells such as histamine and cysteinyl-leukotrienes induce bronchoconstriction, mucus production, plasma exudation, and BHR. Increased expression of T-helper 2 (Th2)-derived cytokines such as interleukin-4 and 5 (IL-4,5) have been observed in the airway mucosa, and these may cause IgE production and terminal differentiation of eosinophils. Chemoattractant cytokines (chemokines) such as eotaxin may be responsible for the chemoattraction of eosinophils to the airways. ${ }^{6-9}$ Asthma can be divided into two principal types named intrinsic and extrinsic asthma. Intrinsic asthma triggered by boggy membranes, congested tissues, and other native causes such as adrenalin stress or exertion and generally develops later in life and virtually nothing is known of its causes. Intrinsic bronchial hyperactivity can be triggered by infection, drugs such as aspirin. In contrast, extrinsic asthma triggered by external agents and allergens. Most cases of extrinsic asthma have an allergic origin and are caused by an IgE-mediated response to an inhaled allergen., This is the type of asthma commonly diagnosed in early life. It carries a better prognosis than extrinsic asthma. Many patients with extrinsic asthma may respond to immunotherapy such as using of recombinant allergens. These exciting novel therapies provide not only promise of new therapies for asthma but also valuable tools for investigation of asthma mechanisms. ${ }^{6,10}$ This review provides an overview of using of recombinant allergens as new therapeutic options for asthma.

\section{Allergen}

Allergens are antigens capable of stimulating type-I hypersensitivity reaction in atopic individuals through Immunoglobulin E (IgE) responses. ${ }^{11,12}$ In the other words, allergens are mostly innocuous antigens that elicit powerful $\mathrm{T}$ helper cell type 2 (Th2) responses leading to hyper-IgE production and allergy. ${ }^{9}$ IgE antibodies, bound to basophils in circulation and mast cells in tissue, cause these cells to release chemicals when they come into contact with an allergen. These chemicals can cause injury to surrounding tissue - the visible signs of an allergy. The (detrimental) reaction may result after exposure via ingestion, inhalation, injection, or contact with skin. A greater understanding of the molecular features that make proteins allergenic will help define new therapeutic targets aimed at blocking allergen recognition and protease activity. ${ }^{9}$ A classic food allergy is an IgE-mediated reaction manifesting as any combination of respiratory, cutaneous, gastrointestinal, 
cardiovascular, and pulmonary symptoms. The most commonly implicated foods include cow's milk, egg, peanut, tree nut, soy, wheat, shellfish, and fish. ${ }^{13}$

Progress in molecular biology and analytical chemistry in the past two decades have facilitated the identification of food allergens and their sequential IgE-binding epitopes. The production of recombinant allergens and the use of threedimensional structural analysis have also contributed to this progress. Although there are a number of limitations associated with studies of food allergen components and epitopes, the detection and quantification of serum IgE antibodies specific to allergen components and epitope peptides are useful for the diagnosis and prognosis of food allergy. In addition, clarification of the sensitization patterns of allergen components in individual patients might facilitate allergen-specific immunotherapy of food allergy. However, numerous issues remain to be investigated. For example, conformational IgE epitopes and T-cell epitopes have not yet been identified for most food allergens, even those for which the threedimensional structure has been determined. Moreover, many allergens remain unidentified because of biodiversity, especially in seafood, and the disposition and digestion of food allergens after ingestion have not been clarified. ${ }^{14}$

\section{Classification and Characterization of Allergens}

Understanding of classification of allergens is important because allergic patients are sensitized by a variety of allergens. Some of them are common such as food allergens (the most common are milk, fruit, fish, eggs, and nuts), pollen, mold, house dust (contains mites as well as dander from house pets), venom from insects (such as bees, wasps, and mosquitoes), or scorpions, plant oil (especially poison ivy, oak, or sumac). ${ }^{15}$ There are many types of allergens such as oligosaccharides and proteins allergens. Protein allergens are very important because they are most abundant allergen in our body and environment. ${ }^{11,15}$

\section{Characterization of Allergens}

Allergens are derived from proteins with a variety of biologic functions, including proteases, ligand-binding proteins, structural proteins, pathogenesis-related proteins, lipid transfer proteins, profilins, and calcium-binding proteins. Biological function, such as the proteolytic enzyme allergens of dust mites, might directly influence the development of IgE responses and might initiate inflammatory responses in the lung that are associated with asthma. Intrinsic structural or biological properties might also influence the extent to which allergens persist in indoor and outdoor environments or retain their allergenicity in the digestive tract. Analyses of the protein family database suggest that the universe of allergens comprises more than 120 distinct protein families. Structural biology and proteomics define recombinant allergen targets for diagnostic and therapeutic purposes and identify motifs, patterns, and structures of immunologic significance. ${ }^{15}$

Peanut allergy is of particular worry given that it leads to fatal reactions more commonly than other foods. In study evaluating fatal food reactions, $62.5 \%$ of fatalities were thought to be by reason of peanut. Peanut allergy can develop in adulthood or childhood and is not as likely to be outgrown. A recent study found that a lower peanut-specific IgE level and a smaller wheal size on peanut SPT anticipated a higher rate of resolution of peanut allergy. ${ }^{13}$

Fish allergy can develop in adulthood. Clinical crossreactivity between fish is $50 \%$; consequently, all fish should be abstained unless an oral challenge confirms tolerance to specific fish. Most patients with fish allergy are able to tolerate shellfish and vice versa. ${ }^{13}$

Nonceliac gluten sensitivity is a clinical entity with GI and extraintestinal features that requires exclusion of $\mathrm{CD}$ and WA for proper interpretation because of the overlapping particularity of these disorders.$^{16}$

Food allergenic chitinases are a relatively small group of proteins, but their relevance as allergens cannot be underestimated given their existence in highly consumed fruits and plant derivatives. It is therefore necessary to have a clear representation of their diffusion, allergenic potency, and structural characteristics. We have reported an updated collection of all the allergenic chitinases identified in food, including information on their molecular analysis. The confirmation that the allergenicity of chitinases is not limited to the hevein-like chitin-binding module and the identification of the first allergenic chitinase outside of the plant kingdom. These findings indicate that further efforts are still needed to achieve a robust characterization of allergenic chitinases (and also of all the other allergens). ${ }^{17}$

\section{Classification of Allergens}

\section{Structural Classification of Allergens}

A structural classification of allergens whose threedimensional structures have been experimentally determined or inferred from sequence similarity showed a restricted distribution similar to the distribution of allergens into sequence-based Pfam families (a large collection of protein families). Allergens were found in all structural classes, as defined by SCOP (Structure Classification of Protein). ${ }^{11,15,18}$ Structural classes of all protein families that contain allergens are classified in all $\alpha$ proteins (392 superfamilies), all $\beta$ proteins (300 superfamilies), $\alpha$ and $\beta$ proteins $(\mathrm{a} / \mathrm{b})$ (221 superfamilies), $\alpha$ and $\beta$ proteins ( $\mathrm{a}+\mathrm{b})$ (424 superfamilies), multidomain proteins (48 superfamilies), membrane and cell-surface proteins (90 superfamilies), small proteins (114 superfamilies), and coiled coil proteins(50 superfamilies). ${ }^{18}$

\section{Functional classification of allergens}

One-sixth of all allergens in AllFam (119 allergens) were inferred to possess hydrolase activity. Half of them (58 allergens) were proteases, such as trypsin-like and subtilisin-like serine proteases (14 and 13 allergens, respectively), and papain-like cysteine proteases (10 allergens). Other hydrolytic enzymes included polygalacturonases (8 allergens), lipases ( 8 allergens), and ribosome-inactivating proteins (8 allergens). ${ }^{18}$

Many allergens bound metal ions. These included calcium-binding allergens from the EF-hand family (32 allergens), serum albumins (12 allergens), globins ( 9 allergens), enolases (9 allergens), and Fe/Mn superoxide dismutases (7 allergens). Allergens with lipid-binding activity comprised nonspecific lipid transfer proteins (nsLTPs) from the prolamin superfamily (28 allergens), serum albumins (12 allergens), and lipocalins (9 allergens). Although not annotated in the Gene Ontology (GO) database, lipid-binding activity was shown for 
allergens from several other families, such as Bet v 1-related allergens that bind plant steroids. ${ }^{18}$

The nonmetabolic biologic process associated with the greatest number of allergens was transport. This group of allergens comprised lipid-binding proteins, such as the nsLTPs (28 allergens) and lipocalins (21 allergens), as well as general carrier proteins, such as serum albumins (12 allergens) and caseins (12 allergens). Many allergens from the cupin and prolamin superfamilies (26 and 22 allergens, respectively) were annotated as nutrient reservoirs. ${ }^{18}$

Of the 203 allergens without GO annotations, 112 were not assigned to a protein family, in most cases because their sequences were too short. The remaining 91 sequences were grouped into 17 AllFam families, with tropomyosins (34 allergens), group 2 mite allergens (10 allergens), thaumatin-like proteins (9 allergens), Ole e 1-related proteins ( 9 allergens), and pectate lyases ( 9 allergens) as the prevailing families. ${ }^{18}$

There are several epitopes on the surface of protein antigens that are flexible and bind with antibodies. ${ }^{19}$ Allergen proteins are a category of antigens that interact with $\operatorname{IgE}$. It is thought that fragments unique to allergens, and that are not found in nonallergen proteins are located at the surface of these proteins ${ }^{20}$ Fragments unique to allergens that have potential flexibility for binding with IgE are thus thought to exist. ${ }^{11}$

Allergens and air pollutants cause mitochondrial dysfunction and mtROS-mediated systemic inflammation, which is crucial in the pathogenesis of allergy, asthma, and MetS, individually. Research is increasingly providing evidence that inflammation during any one of these conditions can drive the pathogenesis of another, establishing a bidirectional causeand-effect relationship. With increased persistence of air pollutants and allergies, a common effective therapy for the comorbidities is needed. While mitochondrial antioxidant coenzymes Q10 and Mito Q are an effort in that direction and have entered clinical trials, mitochondrial transfer therapy is potentially promising in skewing the cellular heteroplasmy in favor of healthy mitochondrial numbers and has met with success in many experimental animal models. Mitochondrial targeted therapy, therefore, merits greater research focus in mtROS-linked disorders. ${ }^{21}$

Lipocalins may, independent of their mammalian other animal, or plant origin, house siderophore ligands, which critically determine their innate immunomodulatory as well as allergenic characteristics. It has been shown that in loaded state human lipocalins induce regulatory $\mathrm{T}$ cells, whereas empty lipocalins rather promote Th2 responses and inflammation. To this end, the interplay between exogenous lipocalins and human LCNs is not resolved. ${ }^{22}$

\section{Strategies for Asthma Management, Prevention, and Treatment}

During the past two decades, many scientific advances have improved our understanding of asthma and our ability to manage and control it effectively. Here, we will describe several strategies for asthma management and prevention that were explained in the following.

\section{Lifestyle Modification}

Avoidance of triggers is a key component of improving control and preventing attacks. The most common triggers include allergens, smoke (tobacco and other), air pollution, non-selective beta-blockers, and sulfite-containing foods. ${ }^{1}$ Cigarette smoking and second-hand smoke (passive smoke) may reduce the effectiveness of medications such as corticosteroids. ${ }^{23}$ Dust mite control measures, including air filtration, chemicals to kill mites, vacuuming, mattress covers, and other methods had no effect on asthma symptoms. ${ }^{24}$

\section{Using of Drugs}

These drugs are included corticosteroids, ${ }^{24}$ beta-adrenergic receptor agonists, ${ }^{25-27}$ anticholinergic drugs, ${ }^{28}$ theophylline, ${ }^{29-34}$ leukotriene modifiers, ${ }^{35}$ cromolyn, ${ }^{35}$ and nedocromil..${ }^{36,37}$

\section{Allergen-Based Immunotherapy}

Immunotherapy is a therapy designed to induce changes in a patient's immune status in order to treat disease. ${ }^{38}$ Immunotherapy for allergic diseases represents an important but largely unmet medical need. Conventional immunotherapy suffers from several breakdowns related to the quality of the extracts used, the risk of inducing anaphylactic reactions, and the extremely long treatment time but recently in immunotherapy for allergic diseases, using of immunologic agents to therapically enhance or suppress the immune system are common. Agents used in immunotherapy include monoclonal antibodies, vaccines, IgE blocker, and recombinant allergens. These agents may also have a direct antitumor effect. ${ }^{39}$ ${ }^{40}$ New therapeutic strategies based on recombinant technology include peptide-based vaccines, engineered hypoallergens with reduced IgE-binding properties, nucleotide-conjugated vaccines that promote Th1 responses, and the possibility of developing prophylactic allergen vaccines. ${ }^{4}$

Many of the problems associated with using natural allergenic products for allergy diagnosis and treatment can be overcome using genetically engineered recombinant allergens. $^{42}$

\section{Methods for Supply Allergens}

There are many methods for gaining allergens contained such as the Ro/SS-A anti-Ro/SS-A system, ${ }^{43-46}$ using solid-phase immunoadsorption system, ${ }^{47}$ extraction of serum, ${ }^{48}$ recombinant technology. ${ }^{12,42,49-51}$

\section{Ro/SS-A Anti-Ro/SS-A System}

This system has achieved increasing diagnostic and pathogenetic relevance and several groups have attempted to isolate and characterize this cellular antigen. The methods commonly employed in the isolation of Ro/SS-A antigen rely on the use of immune affinity columns using naturally occurring specific autoantibodies. ${ }^{43},{ }^{44}$ However, this approach is limited because of low yield and poor standardization. Moreover, a partial denaturation of the antigen can occur during the elution procedures. In the present work, we describe a simple method for the biochemical purification of Ro/SS-A antigen from human spleen by fast protein liquid chromatography (FPLC). ${ }^{45}$ Dong-Hai et al (1998) isolated Ro/SS-A antigen from human spleen by a two-step procedure. In the first step, most of the nonantigenic material was removed by means of ammonium sulphate precipitation and ion exchange chromatography. The final purification was obtained by passing the Ro/SS-Acontaming fractions twice through a Mono Q ion exchange FPLC column. The purified antigen showed identical 
immunoreactivity with crude material on CIE and was composed of two polypeptides with a molecular weight of approximately 60,000 and 55,000, respectively, on SDS-PAGE, both reacting on Western blotting with a panel of anti-Ro/SS-A antisera. This system permits milligrams of highly purified antigen to be obtained from grams of human spleen. ${ }^{46}$

\section{Using Solid-Phase Immunoadsorption System}

Koon Yan Paketal (1983) extracted Circulating Gastrointestinal Cancer Antigen by using of solid-phase immunoadsorption system of monoclonal antibody-coupled membrane. This system is an immunoadsorption system of monoclonal antibody immobilized on a polyolefin alloy fiber. This methodology provides a selective and convenient means of removing any targeted substance by monoclonal antibody from the serum, and thus overcomes many of the shortcomings associated with conventional plasmapheresis. ${ }^{47}$

\section{Extraction from Serum}

Terry et al extracted the carbohydrate-defined class of Ia antigens from murine spleen cells and serum. The final extract contains mostly glycolipid, with small amounts of contaminating phospholipids and little or no protein. ${ }^{48}$

\section{Recombinant Technology for Producing Recombinant Allergens}

Recombinant technologies, as a part of biotechnology, developed in the 1980s for cloning cDNA from low-abundance mRNA permitted the cloning of allergens. ${ }^{49}$ Recombinant allergens will enable innovative new strategies for allergen immunotherapy to be developed. These include peptide-based vaccines, engineered hypoallergens with reduced reactivity for IgE antibodies, nucleotide-conjugated vaccines that promote Th1 responses, and the possibility of developing prophylactic allergen vaccines. ${ }^{52} \mathrm{~A}$ great variety of recombinant plant, mite, mold, mammal, and insect allergens have been expressed in heterologous hosts (e.g., Escherichia coli), their cDNA being used as a template. ${ }^{15,49}$

Many of the problems associated with using natural allergenic products for allergy diagnosis and treatment can be overcome using genetically engineered recombinant allergens. ${ }^{52}$ Recombinant allergens have been used for successful in vitro, as well as in vivo, allergy diagnosis, and work is in progress to produce recombinant allergen derivatives with reduced anaphylactic potential to improve current forms of immunotherapy. Recombinant allergens have proven to be valuable tools to investigate T-cell and B-cell recognition of allergens as well as to study mechanisms of specific IgE regulation. The immunologic equivalence of many relevant recombinant allergens with their natural counterparts has been demonstrated. The number of biologically active recombinant allergens available for experimental, diagnostic, and therapeutic purposes is increasing tremendously. ${ }^{42}$ Recombinant allergens offer the perspective of molecule-based allergy diagnosis and consequently safe and patient-tailored immunotherapy. ${ }^{12}$ Allergens have diverse biological functions (they may be enzymes, enzyme inhibitors, lipocalins, or structural proteins). Recombinant allergens show comparable IgE antibody binding to natural allergens and show excellent reactivity on skin testing and in in vitro diagnostic tests. ${ }^{52}$

\section{Advantages and Disadvantages of Recombinant Allergens}

Recombinant allergens have many advantages that make them as drugs for treatment of asthma. ${ }^{12,42}$ By using recombinant DNA technology for producing recombinant allergens, we use molecules with defined amino acid sequence and other advantages that are preparations of consistent pharmaceutical quality, all batches of one allergen derive from the same master cell bank, avoidance of possible contamination and the risk of infectious agents, dosage in mass units in respect of all components: absolute standardization, inclusion of only the relevant proteins, optimization of the dosage of all components of a preparation, possibility to tailor preparations to a patient's sensitization profile, precise monitoring and investigation of mechanisms underlying treatment, option to create genetically engineered variants (e.g., with reduced $\operatorname{IgE}$ reactivity). ${ }^{12,42,51}$ Although recombinant allergens have some disadvantages such as each allergen has to be developed by using a specific approach, for those allergens occurring in many isoforms, there is a need to choose the most relevant, it might be necessary to include $>1$ isoallergen in cases of limited identity, There are high development costs in relation to limited market potential. ${ }^{51}$

\section{Expression Systems of Recombinant Allergens}

High-level expression systems have been developed to produce recombinant allergens in bacteria, ${ }^{53-62}$ yeast, ${ }^{63-66}$ insect cells, ${ }^{67-71}$ transgenic plant, ${ }^{72-75}$ animal cells, and transgenic animal. ${ }^{76-79}$ These are argued in the following sections.

\section{Bacteria}

Bacterial system has the advantage that it is easy to handle and often results in high expression levels of the recombinant protein. However proteins expressed in E. coli often accumulate in insoluble inclusion bodies, and therefore require chemical refolding procedures to obtain the protein in a native, biological active form. ${ }^{53}$ Furthermore, bacterial expression systems lack the ability to perform protein glycosylation, and therefore allergens that normally occur as glycoproteins are expressed devoid of carbohydrate moieties. In the case of the glycoprotein Phl p 1, the group 1 allergen of the grass $\mathrm{P}$ pratense, expression without the carbohydrate component appears not to have any appreciable effect on IgE antibody binding or T-cell reactivity ${ }^{5,55}$ or on the ability to induce allergen-specific IgG1 and IgG4 responses. ${ }^{56}$ Valenta et al (2010) described that expression of rBet $\mathrm{v} 1$ and $\mathrm{rBet} \mathrm{v} 2$ similar to the natural allergen was also readily accomplished in E coli.19. ${ }^{57}$ In the other study, synthetic genes coding for 2 hybrid proteins consisting of reassembled Der p 1 and Der p 2 fragments with (recombinant Der p 2 [rDer p 2]/1C) and without (rDer p 2/1S) cysteines were expressed in E. coli and purified to homogeneity by means of affinity chromatography ${ }^{58}$ Recombinant Fel d 1 chains expressed individually in E. coli do not bind IgE as well as natural allergen but can be combined and refolded to produce immunoreactive recombinant Fel d $1 .^{59-61}$ Hyaluronidase (Hya) is one of several allergens in honeybee venom, has been cloned $^{62}$ and expressed as a recombinant protein in E. coli. ${ }^{53}$ 


\section{Yeast}

Chua et al..$^{63}$ in 1992 produced a high level of Der $\mathrm{p}$ I from a Cup1 gene cassette from pYELC5-13T in Saccharomyces cerevisiae. ${ }^{63}$ Allergens that did not initially fold correctly in E. coli were eventually produced in other hosts. The hornet allergen Dol $\mathrm{m} 5$ is produced as a well-folded allergen when expressed in the yeast Pichia pastoris. ${ }^{64}$ Cenk Suphioglu et al in Australia expressed Cyn $\mathrm{d} 1$ (from Bermuda grass) in the yeast P. pastoris. ${ }^{65}$ Patricia Barral reported the expression of the olive pollen allergen Ole e 6 in P. pastoris as a soluble and stable protein. Purification to homogeneity, molecular, spectroscopic, and immunological characterization is also described. ${ }^{66}$

\section{Insect Cells}

Baculovirus vectors allow the expression of large foreign gene products from single proteins under $20 \mathrm{kDa}$ to enzymes and multimeric protein assemblies over 1 million Daltons, ${ }^{67,68}$ Furthermore, this system is adapted for simultaneous expression of several foreign gene, using a single recombinant baculovirus. ${ }^{69}$ Dolm 5 from the white-faced hornet (Dolichovespula maculate) be cloned with recombinant DNA technology. ${ }^{70}$ One of several allergens in honeybee venom named Hya expressed as a recombinant protein in baculovirus-infected insect cells. ${ }^{53}$ Acid phosphatase (Api m 3 ) is a major allergen in honeybee (Apis mellifera) venom. Recombinant Api $\mathrm{m} 3$, expressed in Trichoplusia ni cells. The availability of recombinant Api $\mathrm{m} 3$ provides a tool for both the development of improved diagnostic tests and the design of safer and more effective immunotherapeutic approaches for honeybee venom allergy. ${ }^{71}$

\section{Transgenic Plant}

Smart et $\mathrm{al}^{72}$ produced a genetically modified (GM) plant, narrow leaf lupin (Lupinus angustifolius L.), expressing a gene for a potential allergen (sunflower seed albumin) (SSA-lupin) and demonstrate that a GM plant-based vaccine can promote a protective immune response and attenuate experimental asthma, suggesting that plant-based vaccines may be potentially therapeutic for the protection against allergic diseases. ${ }^{72}$ Bet v 1 from birch pollen (Betula verrucosa) is one of the first allergens that ca be cloned with recombinant DNA technology. ${ }^{69,70}$ Scientist can produce a transgenic rice plants expressing mouse dominant $\mathrm{T}$ cell epitope, peptides of Cry $\mathrm{j}$ I and Cry j II allergens of Japanese cedar pollen as a fusion protein with the soybean seed storage protein glycinin. Under the control of the rice seed storage protein glutelin GluB-1 promoter, the fusion protein was specifically expressed and accumulated in seeds at a level of $0.5 \%$ of the total seed protein. ${ }^{75}$

\section{Animal Cells}

Der $\mathrm{p}$ 1, a major allergen from Dermatophagoides pteronyssinus, which plays a prominent role in IgE-mediated immediate hypersensitivity reactions including asthma be cloned with recombinant DNA technology ${ }^{76}$ and be expressed as a recombinant precursor form of Der $\mathrm{p} 1$, recProDer $\mathrm{p} 1,{ }^{77}$ secreted by anchorage-dependent $\mathrm{CHO}$ cells cultured in cell factories. To increase the ProDer $\mathrm{p} 1$ expression level and purification yield, a recombinant $\mathrm{CHO}-\mathrm{K} 1$ clone was adapted ${ }^{78}$ to growth in serumfree suspension culture. In a study, high-level expression of recProDer $\mathrm{p} 1$ were obtained in cultures of the adapted $\mathrm{CHO}$ $\mathrm{K} 1$ cell line (4846-6) in a controlled stirred tank bioreactor. ${ }^{79}$

\section{Conclusion and Perspective of Recombinant Allergens}

The prevalence of asthma is rapidly increasing so that using of allergen-based immunotherapy for the treatment and eventually prevention of IgE-mediated allergy are developing. The broad applicability of allergen-specific immunotherapy is limited by the poor quality and allergenic activity of natural allergen extracts that are used for the production of current allergy vaccines. Many of the problems associated with using natural allergenic products for allergy diagnosis and treatment can be overcome with the use of genetically engineered recombinant allergens. Recombinant allergens are effectively proteins that can be produced at will, under defined conditions, and purified with use of single-step procedures such as affinity chromatography. The expression of a recombinant allergen molecule could be a suitable strategy for the development of in vitro diagnosis test as well as for specific immunotherapy. This has tremendous advantages in terms of quality control and standardization. Although there are some problems, such as low expression and production of misfolded proteins, in process of using of recombinant technology. Problems in recombinant allergen expression in a particular vector can be overcome by choosing a different expression system or by engineering the allergen sequences that enable the protein to assume the correct tertiary structure. Recombinant technology holds the promises that recombinant allergen-based immunotherapy will improve current immunotherapy practice and may open possibilities for new treatment strategies and possibly even for prophylactic vaccination.

\section{Conflicts of Interest Disclosure}

Authors declare no conflict of interest.

\section{References}

1. National Heart L, Institute B. National Asthma Education and Prevention Program. Expert panel report 3: guidelines for the diagnosis and management of asthma: Full report 2007. http://www nhlbi nih gov/ guidelines/asthma/asthgdln pdf. 2007

2. Hill AT, Sullivan AL, Chalmers JD, De Soyza A, Elborn JS, Floto RA, et al. British Thoracic Society guideline for bronchiectasis in adults. Thorax. 2019;74(Suppl 1):1-69.

3. Polk BI, Dinakar C. Management of acute loss of asthma control: Yellow zone strategies. Curr. Opin Aller Clin Immunol. 2019;19(2):154-60.

4. Network GA. The Global Asthma Report A, New Zealand. 2018.

5. Dharmage SC, Perret J, Custovic A. Epidemiology of asthma in children and adults. Front Pediat. 2019;7:246

6. Matricardi PM, Dramburg S, Potapova E, Skevaki C, Renz H. Molecular diagnosis for allergen immunotherapy. J Allerg Clin Immunol. 2019;143(3):831-43.

7. Westman M, Asarnoj A, Hamsten C, Wickman M, van Hage M, editors. Windows of opportunity for tolerance induction for allergy by studying the evolution of allergic sensitization in birth cohorts. Semin Immunol; 2017: Elsevier.

8. Bush A. Pathophysiological mechanisms of asthma. Front Pediat. 2019;7.

9. Shakib F, Ghaemmaghami AM, Sewell HF. The molecular basis of allergenicity. Trends Immunol. 2008;29(12):633-42.

10. Frew AJ. Immunotherapy of allergic disease. Clin Immunolo: Elsevier; 2019 p. 1227-35. e1.

11. Asakawa N, Sakiyama N, Teshima R, Mitaku S. Characteristic amino acid distribution around segments unique to allergens. J Biochem. 2009;147(1):127-33.

12. Egger M, Hauser M, Himly M, Wopfner N, Wallner M, Ferreira F. Development of recombinant allergens for diagnosis and therapy. Front Biosci (Elite edition). 2009;1:77-90. 
13. Patel BY, Volcheck GW, editors. Food allergy: Common causes, diagnosis, and treatment. Mayo Clin Proc; 2015: Elsevier.

14. Matsuo H, Yokooji T, Taogoshi T. Common food allergens and their lgEbinding epitopes. Allergol Int. 2015:64(4):332-43.

15. Chapman M, Smith A, Vailes L, Arruda L. Recombinant mite allergens: new technologies for the management of patients with asthma. Allergy. 1997;52(4):374-9.

16. Fasano A, Sapone A, Zevallos V, Schuppan D. Nonceliac gluten sensitivity. Gastroenterology. 2015;148(6):1195-204.

17. Leoni C, Volpicella M, Dileo MC, Gattulli BA, Ceci LR. Chitinases as food allergens. Molecules. 2019;24(11):2087.

18. Radauer C, Bublin M, Wagner S, Mari A, Breiteneder H. Allergens are distributed into few protein families and possess a restricted number of biochemical functions. J Allerg Clin Immunol. 2008;121(4):847-52. e7.

19. Demchenko AP. Recognition between flexible protein molecules: Induced and assisted folding. J Mol Recog. 2001;14(1):42-61.

20. Zorzet A, Gustafsson M, Hammerling U. Prediction of food protein allergenicity: A bio-informatic learning systems approach. In Silico Biol. 2002;2(4):525-34.

21. Iyer D, Mishra N, Agrawal A. Mitochondrial function in allergic disease. Curr Allerg Asthma Rep. 2017;17(5):29.

22. Jensen-Jarolim E, Pacios L, Bianchini R, Hofstetter G, Roth-Walter F. Structural similarities of human and mammalian lipocalins, and their function in innate immunity and allergy. Allergy. 2016;71(3):286-94.

23. Stapleton M, Howard-Thompson A, George C, Hoover RM, SelfTH. Smoking and asthma. J Am Board Family Med. 2011;24(3):313-22.

24. Martinez F. Genes, environments, development and asthma: a reappraisal. Eur Resp J. 2007;29(1):179-84.

25. Palmqvist M, Persson G, Lazer L, Rosenborg J, Larsson P, Lotvall J. Inhaled dry-powder formoterol and salmeterol in asthmatic patients: onset of action, duration of effect and potency. Eur Resp J. 1997;10(11):2484-9.

26. Usmani OS, Ito K, Maneechotesuwan K, Ito M, Johnson M, Barnes PJ, et al. Glucocorticoid receptor nuclear translocation in airway cells after inhaled combination therapy. Am J Resp Critic Care Med. 2005;172(6):704-12.

27. ANDREW McIVOR R, Pizzichini E, Turner MO, Hussack P, Hargreave FE, Sears MR. Potential masking effects of salmeterol on airway inflammation in asthma. Am J Resp Critical Care Med. 1998;158(3):924-30.

28. Barash PG. Clinical anesthesia: Lippincott Williams \& Wilkins; 2009

29. Essayan DM. Cyclic nucleotide phosphodiesterases. J Aller Clin Immunol. 2001:108(5):671-80.

30. Deree J, Martins JO, Melbostad H, Loomis WH, Coimbra R. Insights into the regulation of TNF-a production in human mononuclear cells: the effects of non-specific phosphodiesterase inhibition. Clinics. 2008;63(3): $321-8$.

31. Marques $L J$, Zheng L, Poulakis N, GUZMAN J, Costabel U. Pentoxifylline inhibits TNF-a production from human alveolar macrophages. Am J Resp Critical Care. 1999:159(2):508-11.

32. Peters-Golden M, Canetti C, Mancuso P, Coffey MJ. Leukotrienes: Underappreciated mediators of innate immune responses. J Immunol. 2005:174(2):589-94.

33. Daly J, Jacobson K, Ukena D. Adenosine receptors: development of selective agonists and antagonists. Prog Clin Biol Res. 1987;230:41-63.

34. Yano Y, Yoshida M, Hoshino S, Inoue K, Kida H, Yanagita M, et al. Anti-fibrotic effects of theophylline on lung fibroblasts. Biochem Biophys Res Commun. 2006;341(3):684-90.

35. Fanta CH. Drug therapy: asthma. N Engl J Med. 2009;360(10):1002-14

36. Mellis C. Benefits of budesonide or nedocromil for mild to moderate asthma in children were not sustained after discontinuation. Evidence-based Med. 2009;14(6):175-

37. Yang Y, Lu JY-L, Wu X, Summer S, Whoriskey J, Saris C, et al. G-proteincoupled receptor 35 is a target of the asthma drugs cromolyn disodium and nedocromil sodium. Pharmacology. 2010;86(1):1-5.

38. Fitzhugh DJ, Lockey RF. History of immunotherapy: the first 100 years. Immunol Aller Clin. 2011;31(2):149-57.

39. Moingeon P, Batard T, Fadel R, Frati F, Sieber J, Van Overtvelt L. Immune mechanisms of allergen specific sublingual immunotherapy. Allergy. 2006:61(2):151-65

40. Cox L, Li JT, Nelson H, Lockey R. Allergen immunotherapy: A practice parameter second update. J Aller Clin Immunol. 2007;120(3):S25-S85.

41. Crameri R. Allergy diagnosis, allergen repertoires, and their implications fo allergen-specific immunotherapy. Immunol Aller Clin. 2006;26(2):179-89.

42. Zhernov Y, Curin M, Khaitov M, Karaulov A, Valenta R. Recombinant allergens for immunotherapy: state of the art. Curr Opin Aller Clin Immunol. 2019:19(4):402-14.
43. Venables $P$, Smith $P$, Maini R. Purification and characterization of the Sjögren's syndrome A and B antigens. Clin Exp Immunol. 1983;54(3): 731

44. Yamagata H, Harley JB, Reichlin M. Molecular properties of the Ro/SSA antigen and enzyme-linked immunosorbent assay for quantitation of antibody. J Clin Investig. 1984;74(2):625-33.

45. Bilder R. Fast protein liquid chromatography: A new method for analysing large biological molecules. Int Labmate. 1983;8(5).

46. Wu D-H, Tavoni A, Garzelli C, Neri R, Vitali C, Bombardieri S. A simple method for the biochemical purification of Ro/SS-A antigen. J Immunol Methods. 1989:121(2):219-24

47. Pak KY, Randerson DH, Blaszczyk M, Sears HF, Steplewski Z, Koprowski H. Extraction of circulating gastrointestinal cancer antigen using solid-phase immunoadsorption system of monoclonal antibody-coupled membrane. J Immunol Methods. 1984;66(1):51-8.

48. Higgins TJ, Parish CR. Extraction of the carbohydrate-defined class of la antigens from murine spleen cells and serum. Mol Immunol. 1980;17(8):1065-73.

49. Thomas WR. The advent of recombinant allergens and allergen cloning. J Aller Clin Immunol. 2011;127(4):855-9.

50. Valenta R, Linhart B, Swoboda I, Niederberger V. Recombinant allergens for allergen-specific immunotherapy: 10 years anniversary of immunotherapy with recombinant allergens. Allergy. 2011;66(6):775-83.

51. Cromwell $O$, Häfner $D$, Nandy A. Recombinant allergens for specific immunotherapy. J Allerg Clin Immunol. 2011;127(4):865-72.

52. Chapman MD, Smith AM, Vailes LD, Pomés A, editors. Recombinant allergens for immunotherapy. Allergy and Asthma Proceedings; 2002: OceanSide Publications.

53. Dudler T, Chen W-Q, Wang S, Schneider T, Annand RR, Dempcy RO, et al. High-level expression in Escherichia coli and rapid purification of enzymatically active honey bee venom phospholipase A2. Biochim Biophys Acta Lipids Lipid Metab. 1992;1165(2):201-10.

54. Suck R, Kamionka T, Schäffer B, Wahl R, Nandy A, Weber B, et al. Bacterially expressed and optimized recombinant Phl p 1 is immunobiochemically equivalent to natural Phl p 1. Biochim Biophys Acta Proteins Proteom. 2006:1764(11):1701-9.

55. Cromwell O, Fiebig H, Suck R, Kahlert H, Nandy A, Kettner J, et al. Strategies for recombinant allergen vaccines and fruitful results from first clinical studies. Immunol Allerg Clin. 2006;26(2):261-81.

56. Jutel $M$, Jaeger $L$, Suck R, Meyer H, Fiebig H, Cromwell O. Allergen-specific immunotherapy with recombinant grass pollen allergens. J Allerg Clin Immunol. 2005;116(3):608-13.

57. Valenta R, Ferreira F, Focke-Tejkl M, Linhart B, Niederberger V, Swoboda I, et al. From allergen genes to allergy vaccines. Annu Rev Immunol. 2009:28:211-41.

58. Chen K-W, Blatt K, Thomas WR, Swoboda I, Valent P, Valenta R, et al. Hypoallergenic Der $p$ 1/Der $p 2$ combination vaccines for immunotherapy of house dust mite allergy. J Allerg Clin Immunol. 2012;130(2):435-43. e4.

59. Slunt JB, Rogers BL, Chapman MD. IgE antibodies to recombinant forms of Fel d I: Dichotomy between fluid-phase and solid-phase binding studies. J Allerg Clin Immunol. 1995;95(6):1221-8.

60. Keating KM, Segal DB, Craig SJ, Nault AK, Semensi V, Wasserman AS, et al. Enhanced immunoreactivity and preferential heterodimer formation of reassociated Fel d I recombinant chains. Mol Immunol. 1995;32(4):287-93.

61. van Ree R, van Leeuwen WA, Bulder I, Bond J, Aalberse RC. Purified natural and recombinant Fel $\mathrm{d} 1$ and cat albumin in in vitro diagnostics for cat allergy. J Allerg Clin Immunol. 1999;104(6):1223-30.

62. Kuchler K, GMACHL M, SIPPL MJ, KREIL G. Analysis of the cDNA for phospholipase A2 from honeybee venom glands: the deduced amino acid sequence reveals homology to the corresponding vertebrate enzymes. Eur J Biochem. 1989;184(1):249-54.

63. Chua K-Y, Kehal PK, Thomas WR, Vaughan PR, Macreadie IG. High-frequency binding of IgE to the Der p allergen expressed in yeast. J Allerg Clin Immunol. 1992;89(1):95-102

64. Monsalve Rl, Lu G. Expressions of recombinant venom allergen, antigen 5 of yellowjacket (Vespula vulgaris) and paper wasp (Polistes annularis), in bacteria or yeast. Protein Expr Purific. 1999:16(3):410-6.

65. Suphioglu C, Smith PM, Ong EK, Knox RB, Singh MB. Recombinant expression and epitope mapping of grass pollen allergens. New Horiz Allerg Immunother: Springer; 1996. p. 147-55.

66. Barral P, Tejera MaL, Treviño MÁ, Batanero E, Villalba M, Bruix M, et al. Recombinant expression of Ole e 6, a Cys-enriched pollen allergen, in Pichia pastoris yeast: Detection of partial oxidation of methionine by NMR. Protein Expr Purific. 2004;37(2):336-43. 
67. Maiorella B, Inlow D, Shauger A, Harano D. Large-scale insect cell-culture for recombinant protein production. Bio/technology. 1988;6(12):1406.

68. Trowitzsch S, Bieniossek C, Nie Y, Garzoni F, Berger I. New baculovirus expression tools for recombinant protein complex production. J Struct Biol. 2010;172(1):45-54

69. Závodzky P, Cseh S. Production of multidomain complement glycoproteins in insect cells. Insect Cell Culture: Fundam Appl Aspects: Springer; 1996. p. 279-88.

70. Fang K, Vitale M, Fehlner P, King TP. cDNA cloning and primary structure of a white-face hornet venom allergen, antigen 5. Proc Natl Acad Sci. 1988;85(3):895-9.

71. Grunwald T, Bockisch B, Spillner E, Ring J, Bredehorst R, Ollert MW. Molecular cloning and expression in insect cells of honeybee venom allergen acid phosphatase (Api m 3). J Allerg Clin Immunol. 2006;117(4):848-54.

72. Smart V, Foster PS, Rothenberg ME, Higgins T, Hogan S. A plant-based allergy vaccine suppresses experimental asthma via an IFN- $\gamma$ and CD4+ CD45RBlow T cell-dependent mechanism. J Immunol. 2003;171(4):2116-26.

73. Breiteneder H, Hassfeld W, Pettenburger K, Jarolim E, Breitenbach M, Rumpold $\mathrm{H}$, et al. Isolation and characterization of messenger RNA from male inflorescences and pollen of the white birch (Betula verrucosa). Int Arch Allerg Immunol. 1988;87(1):19-24.
74. Breiteneder $H$, Pettenburger $K$, Bito A, Valenta R, Kraft D, Rumpold H et al. The gene coding for the major birch pollen allergen Betv1, is highly homologous to a pea disease resistance response gene. EMBO J. 1989:8(7):1935-8.

75. Takagi H, Hiroi T, Yang L, Tada Y, Yuki Y, Takamura K, et al. A rice-based edible vaccine expressing multiple T cell epitopes induces oral tolerance for inhibition of Th2-mediated IgE responses. Proc Natl Acad Sci. 2005;102(48):17525-30.

76. Chua K, Stewart G, Thomas W, Simpson R, Dilworth R, Plozza T, et al. Sequence analysis of cDNA coding for a major house dust mite allergen, Der p 1. Homology with cysteine proteases. J Exp Med. 1988;167(1):175-82.

77. Massaer M, Mazzu P, Haumont M, Magi M, Daminet V, Bollen A, et al. High-level expression in mammalian cells of recombinant house dust mite allergen ProDer $\mathrm{p} 1$ with optimized codon usage. Int Arch Allerg Immunol. 2001;125(1):32-43.

78. Scharfenberg K, Wagner R. A reliable strategy for the achievement of cell lines growing in protein-free medium. Animal cell technology: Developments towards the 21st century: Springer; 1995. p. 619-23.

79. Coulon L, Touzani OBH, Magi M, Bollen A, Hanus R, Jacquet A. Production of Recombinant Allergen Proder $\mathrm{P} 1$ by CHO Cells Adapted to Grow in SerumFree Suspension. Animal Cell Technology: From Target to Market: Springer; 2001. p. 110-3.

This work is licensed under a Creative Commons Attribution-NonCommercial 3.0 Unported License which allows users to read, copy, distribute and make derivative works for non-commercial purposes from the material, as long as the author of the original work is cited properly. 